\title{
30th anniversary for the developmental origins of endocrinology
}

\author{
Sean W Limesand ${ }^{1}$, Kent L Thornburg ${ }^{2}$ and Jane E Harding ${ }^{3}$ \\ 1School of Animal and Comparative Biomedical Sciences, University of Arizona, Tucson, Arizona, USA \\ ${ }^{2}$ Center for Developmental Health, Knight Cardiovascular Institute, Oregon Health and Science University, Portland, Oregon, USA \\ ${ }^{3}$ Liggins Institute, The University of Auckland, Auckland, New Zealand
}

Correspondence should be addressed to S W Limesand: Limesand@ag.arizona.edu

This paper is part of a thematic section on 30 Years of the Developmental Endocrinology of Health and Disease. The guest editors for this section were Sean Limesand, Kent Thornburg and Jane Harding

This special issue for the Journal of Endocrinology celebrates the 30th anniversary of David Barker's seminal findings that led to the scientific field of the Developmental Origins of Health and Disease (DOHaD) (Fig. 1). In 1989, Barker and colleagues reported that low birth weight and weight at 1 year, proxies for fetal growth restriction, were related to an individual's risk for developing hypertension and cardiovascular heart disease (Barker et al. 1989a,b). Barker's initial epidemiological studies within geographical regions of England demonstrated that low birth weight was predictive of later glucose intolerance, type 2 diabetes and other metabolic-related diseases (Hales et al. 1991, Barker 1998). As the developmental origins concept developed, the number of epidemiological studies continued to expand globally, consistently demonstrating the higher risk of developing chronic degenerative diseases if one was born small (Fleming et al. 2018). In this thematic issue on the early origins of disease, there are a series of review articles and research papers that capture the impact of early events on endocrine systems, as major mechanisms underlying Barker's original observations. Importantly, over the past 30 years as the $\mathrm{DOHaD}$ concept has become widely accepted, we have seen it applied to an ever-expanding breadth of human health problems. This expansion is evidenced by the growth of new model systems and establishment of new causal relationships in neuroendocrinology, reproductive systems, obesity

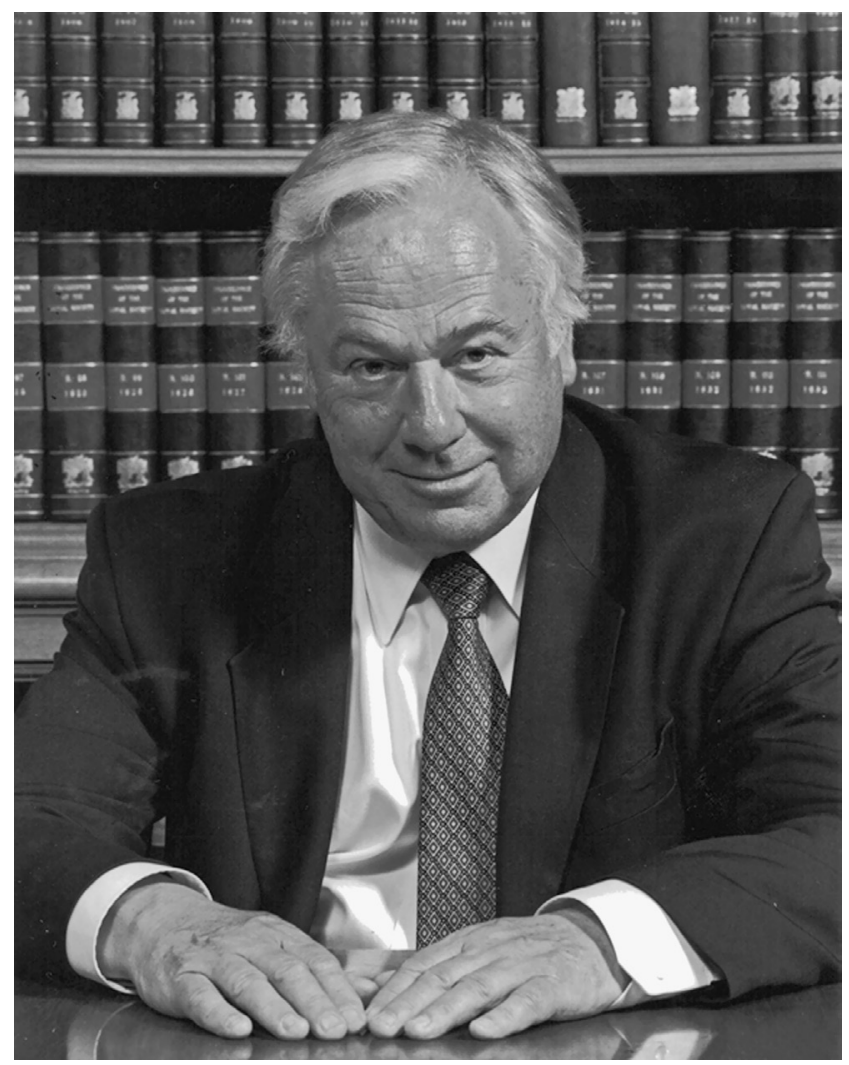

Figure 1

David J P Barker. Photograph taken by Prudence Cuming Associates in 1998, (c) The Royal Society. 
and behavior. The importance of the $\mathrm{DOHaD}$ concept, its continued evolution and new underlying mechanism are captured in the articles of this issue dedicated to Professor Barker's legacy.

Tessa Roseboom (Roseboom 2019) reviews a series of epidemiological studies associated with the tragic Dutch Hunger Winter of 1944-1945 caused by a blockade of food delivery in Nazi-occupied regions of The Netherlands for some 5 months. She describes the negative effects of early undernutrition due to famine on an individual's health and wellness over their life course. The consistent links between maternal undernutrition and adult phenotypes strongly support the concept that early maternal undernutrition and/or stress permanently alters the fetal developmental trajectory. This developmental plasticity has been demonstrated in a number of animal studies where adverse conditions during early development permanently change the physiology and metabolism of the individual. Epigenetic modifications in response to in utero stressors provide a potential mechanism for the altered phenotypic heritability. Dipali Goyal and colleagues (Goyal et al. 2019) review the mechanisms of such epigenetic modifications and present evidence for these in response to intrauterine stresses resulting in increased risk of metabolic-related diseases in adulthood.

The original observations by Barker demonstrated a strong association between low birth weight and later hypertension and cardiovascular disease. Trassanee Chatmethakul and Robert Roghair (Chatmethakul \& Roghair 2019) have reviewed the risk of hypertension following perinatal adversity. They present detailed accounts of the downstream mechanisms underlying hypertension and provide parallels drawn from numerous experimental paradigms. They also note that preterm birth, like intrauterine growth restriction, is a major risk factor for developing hypertension later in life.

In addition to hypertension as a cardiovascular risk factor, two reviews in this issue focus on cardiovascular development and maturation in utero. Rui Song and colleagues (Song et al. 2019) highlight the role of glucocorticoids in the developmental programming of the cardiac microenvironment and heart disease. The heart, like most organs, is pluricellular. The cellular components form a network structure requiring communication among cell types, and exposure to aberrant glucocorticoid concentrations can influence these supporting cells to alter cardiac function. Consistent with this, a predominant risk factor for cardiovascular disease in adulthood is postulated to arise from poor cardiomyocyte proliferation and maturation, which is mediated in part by thyroid hormones. Natasha Chattergoon (Chattergoon 2019) has summarized the role of thyroid hormones in development and specifically discussed their regulation of myocardial development.

An early landmark paper by Barker and Hales (Hales et al. 1991) demonstrated that impaired glucose tolerance was linked to early growth, and subsequent epidemiological studies have shown an association between low birth weight and increased adiposity. Johan Eriksson (Eriksson 2019) presents an in-depth discussion on how early life exposures shape these developmental trajectories and cause defects in insulin sensitivity as well as insulin secretion. He suggests that public health strategies need to shift from exclusively focusing on adults to implementing a life course perspective when studying and preventing type 2 diabetes. This perspective would consider aspects of childhood growth, adiposity and other known factors underpinning type 2 diabetes. Clare Reynolds and Mark Vickers (Reynolds \& Vickers 2019) focus on this developmental aspect of adiposity, discussing the roles of leptin, adiponectin and other adipokines in rodent and large animal models and how they can be used to intervene with some of the disorders produced by developmental responses to nutritional insults. The original hypothesis proposed by Hales and Barker focused on impaired early fetal growth that may have been the result of poor nutrition, but these reviews also point to over-nutrition and maternal diabetes as potentially leading to developmental adaptations and later disease risk. The research paper by Kok Lim Kua and colleagues (Kua et al. 2018) reports on the use of localized feto-maternal infusions to isolate the effects of hyperglycemia and hyperinsulinemia. This study shows that fetal hyperglycemia is responsible for programming skeletal muscle insulin resistance in 3-week-old rat pups.

The role of early life environmental signals in altering physiological processes has now been demonstrated in other critical systems, including the neuroendocrine and reproductive systems. Stephen Matthews and Patrick McGowan (Matthews \& McGowan 2019 review the developmental programming of the hypothalamuspituitary-adrenal axis and the implications for behavioral responses. They present several key aspects of the programming of neurodevelopmental trajectories, glucocorticoid sensitivity and the nature of the stressors, which influence outcomes through epigenetic modifications that have transgenerational effects. Transgenerational effects from developmental programming have also been identified in the reproductive 
system via effects on male and female gametes. Patrycja Jazwiec and Deborah Sloboda (Jazwiec \& Sloboda 2019) review the developmental programming of reproduction, and specifically, gametogenesis. They discuss a substantial body of literature which demonstrate the effects of early life adversity on reproduction, including both overnutrition and undernutrition. A research paper by Lin-guo Pei and colleagues (Pei et al. 2019) reports on the effects of prenatal caffeine exposure and consequent impairment in testicular development and function in offspring. The findings show that insulin-like growth factor 1 expression in the testis is regulated by glucocorticoids, which together produce epigenetic modifications.

The DOHaD concept that originally emerged from David Barker's research has progressed in many directions over the last 30 years. New model systems continue to be developed to test the hypothesis and refine critical developmental windows. Jacqueline Wallace (Wallace 2019) describes a unique paradigm where the nutritional management of weight in adolescent ewes allows investigators to explore the differential effects of maternal energy consumption on the growth status of mother and fetus. Importantly, repartitioning of nutrients during pregnancy in the adolescent mother has negative effects by impairing placental growth and functions that support fetal growth. Although numerous studies have focused on aspects of fetal growth during pregnancy, Miguel Velazquez and colleagues (Velazquez et al. 2019) review a growing consensus of clinical and animal research that shows specific vulnerability of the periconceptional period, when gametes are maturing and embryogenesis is taking place. This review highlights the negative impact of maternal over-nutrition and undernutrition as well as periconceptional programming of paternal gametes.

In summary, three major themes resonate throughout this collection of articles highlighting 30 years of the developmental origins of endocrinology, arising from David Barker's work. The first is that environmental cues during critical windows of development increase an individual's vulnerability to chronic degenerative diseases, affecting their future health and wellbeing. The second is that epigenetic modifications play a significant role in developmental plasticity and ultimately the persistence of the health-related outcomes. Finally, these outcomes may be progressive in nature, meaning that developmental cues trigger downstream cascades of reactions in different biological systems. All these aspects need to be considered in designing early interventions that may delay or avoid disease onset and improve individual wellness, providing important health benefits to the whole population.

\section{Declaration of interest}

Sean Limesand is a Senior Editor of Journal of Endocrinology. Sean Limesand was not involved in the review or editorial process for this paper, on which he is listed as an author. The other authors declare that there is no conflict of interest that could be perceived as prejudicing the impartiality of this editorial.

\section{Funding}

This work did not receive any specific grant from any funding agency in the public, commercial or not-for-profit sector.

\section{Acknowledgements}

The authors thank our colleagues who contributed to this issue.

\section{References}

Barker DJP 1998 Mother, Babies and Health in Later Life. Edinburgh, UK: Churchill Livingstone.

Barker DJ, Osmond C, Golding J, Kuh D \& Wadsworth ME 1989a Growth in utero, blood pressure in childhood and adult life, and mortality from cardiovascular disease. BMJ 298 564-567. (https://doi. org/10.1136/bmj.298.6673.564)

Barker DJ, Winter PD, Osmond C, Margetts B \& Simmonds SJ $1989 b$ Weight in infancy and death from ischaemic heart disease. Lancet 2 577-580. (https://doi.org/10.1016/S0140-6736(89)90710-1)

Chatmethakul T \& Roghair RD 2019 Risk of hypertension following perinatal adversity: IUGR and prematurity. Journal of Endocrinology 242 T21-T32. (https://doi.org/10.1530/JOE-18-0687)

Chattergoon NN 2019 Thyroid hormone signalling and consequences for cardiac development. Journal of Endocrinology 242 T145-T160. (https://doi.org/10.1530/JOE-18-0704)

Eriksson JG 2019 Developmental pathways and programming of diabetes: epidemiological aspects. Journal of Endocrinology 242 T95-T104. (https://doi.org/10.1530/JOE-18-0680)

Fleming TP, Watkins AJ, Velazquez MA, Mathers JC, Prentice AM, Stephenson J, Barker M, Saffery R, Yajnik CS, Eckert JJ, et al. 2018 Origins of lifetime health around the time of conception: causes and consequences. Lancet 391 1842-1852. (https://doi.org/10.1016/ S0140-6736(18)30312-X)

Goyal D, Limesand SW \& Goyal R 2019 Epigenetic responses and the developmental origins of health and disease. Journal of Endocrinology 242 T105-T119. (https://doi.org/10.1530/JOE-19-0009)

Hales CN, Barker DJ, Clark PM, Cox LJ, Fall C, Osmond C \& Winter PD 1991 Fetal and infant growth and impaired glucose tolerance at age 64. BMJ 303 1019-1022. (https://doi.org/10.1136/bmj.303.6809.1019)

Jazwiec PA \& Sloboda DM 2019 Nutritional adversity, sex and reproduction: 30 years of $\mathrm{DOHaD}$ and what have we learned? Journal of Endocrinology 242 T51-T68. (https://doi.org/10.1530/JOE-19-0048)

Kua KL, Hu S, Wang C, Yao J, Dang D, Sawatzke AB, Segar JL, Wang K \& Norris AW 2018 Fetal hyperglycemia acutely induces persistent insulin resistance in skeletal muscle. Journal of Endocrinology $\mathbf{2 4 2}$ M1-M15. (https://doi.org/10.1530/JOE-18-0455) 
Matthews SG \& McGowan PO 2019 Developmental programming of the HPA axis and related behaviours: epigenetic mechanisms. Journal of Endocrinology 242 T69-T79. (https://doi.org/10.1530/JOE-19-0057)

Pei LG, Zhang Q, Yuan C, Liu M, Zou Y, Lv F, Luo D, Zhong S \& Wang H 2019 The GC-IGF1 axis-mediated testicular dysplasia caused by prenatal caffeine exposure. Journal of Endocrinology 242 M17-M32. (https://doi.org/10.1530/JOE-18-0684)

Reynolds CM \& Vickers MH 2019 The role of adipokines in developmental programming: evidence from animal models. Journal of Endocrinology 242 T81-T94. (https://doi.org/10.1530/JOE-18-0686)

Roseboom TJ 2019 Epidemiological evidence for the developmental origins of health and disease: effects of prenatal undernutrition in humans. Journal of Endocrinology 242 T135-T144. (https://doi. org/10.1530/JOE-18-0683)

Song R, Hu X-Q \& Zhang L 2019 Glucocorticoids and programming of the microenvironment in heart. Journal of Endocrinology $\mathbf{2 4 2}$ T121-T133. (https://doi.org/10.1530/JOE-18-0672)

Velazquez MA, Fleming TP \& Watkins AJ 2019 Periconceptional environment and the developmental origins of disease. Journal of Endocrinology 242 T33-T49. (https://doi.org/10.1530/JOE-18-0676) Wallace JM 2019 Competition for nutrients in pregnant adolescents: consequences for maternal, conceptus and offspring endocrine systems. Journal of Endocrinology 242 T1-T19. (https://doi. org/10.1530/JOE-18-0670)

Received in final form 21 May 2019

Accepted 23 May 2019

Accepted Preprint published online 24 May 2019 (c) 2019 Society for Endocrinology Published by Bioscientifica Ltd. 